\title{
Aspects of Creep Behavior of Textile Reinforcements for Composite Materials
}

\author{
André Seidel, Ingolf Lepenies, Thomas Engler , Chokri Cherif and Bernd W. Zastrau
}

\author{
Technische Universität Dresden, Fakultät Maschinenwesen, Institut für Textilmaschinen und Textile \\ Hochleistungswerkstofftechnik (ITM), Ehemals: Institut Für Textil- und Bekleidungstechnik, D-01062 Dresden, \\ Germany
}

\begin{abstract}
Numerous technical applications utilize fiber reinforced composites made with high performance glass and/or carbon fibers. These fibers are especially desirable due to their mechanical and chemical properties resulting in high tensile strength. A relatively new application field is textile reinforced concrete (TRC), which is composed of a textile structure made up of multifilament yarns (rovings) and a cement matrix. To guarantee that the fibers retain their strength over long periods of time in an alkaline milieu, alkaline resistant materials such as alkali-resistant glass fibers (AR-glass) are used. Further requirements placed on textile reinforcements include excellent mechanical properties, such as high strength and stiffness, which remain unchanged or are nominally altered under long-term stresses. These properties will be discussed in this paper within the framework of an experiment conducted, which observed the behavior of AR-glass rovings under continuous long-term stress relative to time. The paper analyzes and interprets the results obtained on the yarns' mechanical properties. The objective was to develop a mechanical model of the material behavior of the textile structures to aid in the prognosis of long-term behavior of textile reinforced composite materials (i.e. textile reinforced concrete).
\end{abstract}

Keywords: AR-glass fibers, long-term stress, long-term behavior, creep, mechanical model, textile reinforcement, fiber reinforced composites.

\section{INTRODUCTION}

Textile fiber materials are increasingly being used as reinforcements in diverse technical applications, such as textile reinforced concrete. To calculate the material behavior of the composite, it is necessary to possess sound knowledge of all the components in the composite, on which the mechanical models are based. The behavior of the mechanical properties of the implemented textile yarns and structures under short-term stresses has been fairly well researched; see for example [1-5]. However, their behavior under long-term stresses is relatively unknown and little information is available even though it is imperative for applications of structural load-bearing components. To guarantee the required structural integrity and lifespan of the component or construction element, it is necessary to determine the changes which may take place in the mechanical properties over longer periods of time; compare [6-8]. Research results evaluating the behavior are generally restricted to applications of fiber reinforced plastic composites, such as those with thermoplastics as the base matrix $[9,10]$. However, the experimental approach can be applied to textile reinforcements for concrete.

In experiments conducted with AR-glass rovings under long-term stress, time relevant changes in the material behavior of the yarns could be observed. Experiments conducted by [11] on long-term, continuously stressed

\footnotetext{
*Address correspondence to this author at the Technische Universität Dresden, Fakultät Maschinenwesen, Institut für Textilmaschinen und Textile Hochleistungswerkstofftechnik (ITM), Ehemals: Institut Für Textilund Bekleidungstechnik, D-01062 Dresden, Germany; Tel: +49 (0)351 463 34795; Fax: +49 (0)351 463 34026; E-mail: thomas.engler@tu-dresden.de
}

filament yarns over an observation period of hours to days, show verifiable retardation effects under constant tensile strength and relaxation under constant application of strain. Due to these observations, extensive experiments were conducted on the long-term stress effects on AR-glass rovings over a period of several months. Creep behavior could be identified relative to time and verified in magnitude. These results were used to create a mechanical model based on rheological methods. The mechanical model diagrams the observed change in behavior over a given period of time and aids in the prognosis of long-term behavior of the implemented fiber materials.

\section{EXPERIMENTAL INVESTIGATIONS}

In order to investigate the long term behavior of the ARglass rovings in more detail several yarns are observed under permanent tensile loads ( 80 to $90 \%$ of failure load). To accomplish this, an experimental test bed was constructed as diagrammed in Fig. (1). A test block was hung on a $26 \mathrm{~m}$ long roving and loaded with a constant weight. An inductive displacement transducer continuously measured the increase in length during a set observation period. These experiments were conducted over a period of weeks and up to several months (the longest recorded time period was 5 months).

The following results were derived:

- $\quad$ During the first day the observed glass fiber yarns showed a significant increase in elongation, about 5 to $10 \%$ related to the initial elastic strain due to the external load.

- $\quad$ After a longer period of time additional deformation between 3 to $5 \%$ related to the initial deforma-tion after the first day is observed. In Fig. (1), the relation 

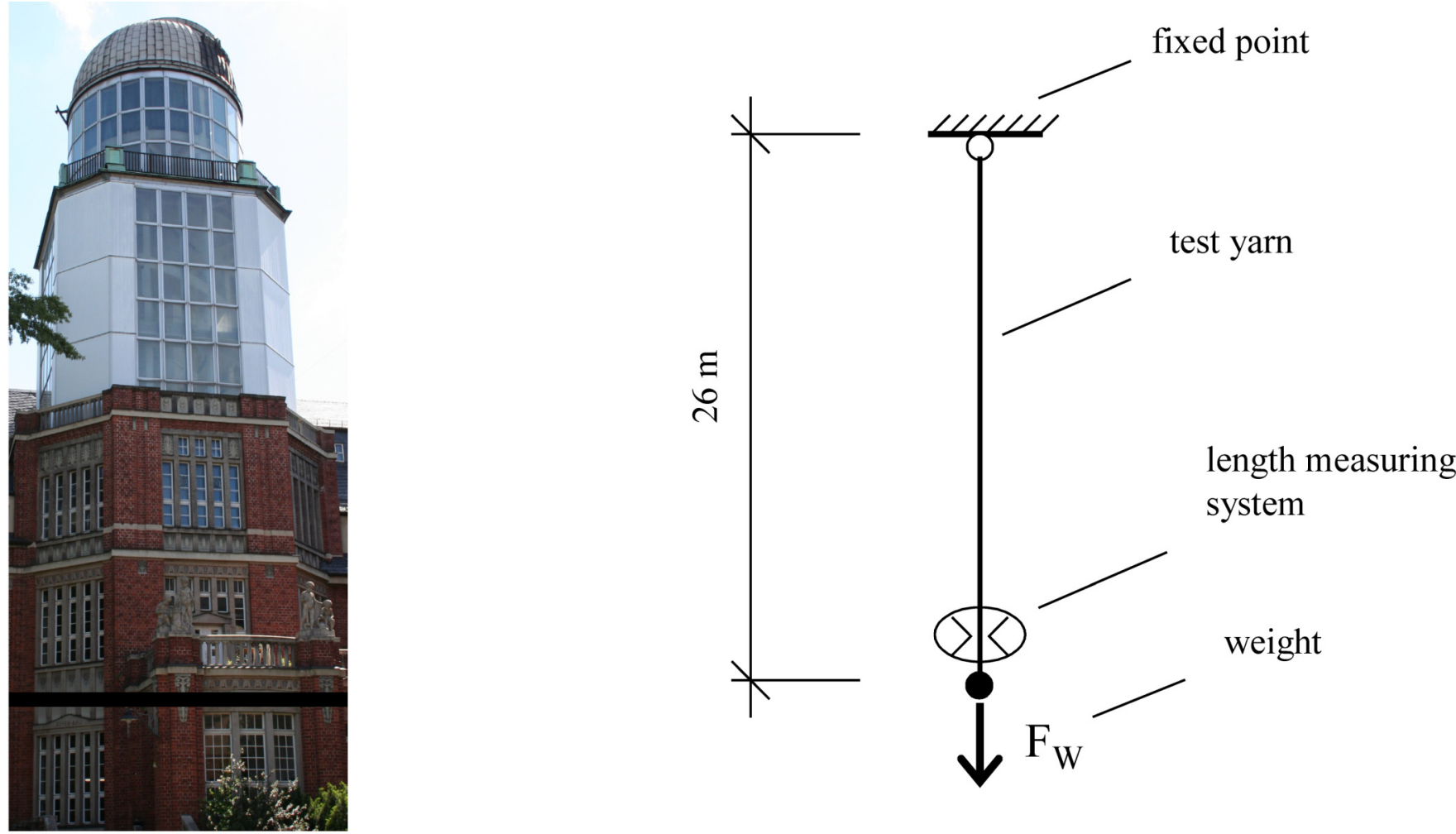

Fig. (1). Test bed to determine the long-term behavior of constantly loaded rovings; building (tower) where experiment took place and schematic diagram.

between deformation and the time interval is shown for one of the sample experiments.

- $\quad$ The achieved results in all experiments show a similar behavior with small scattering.

The paper deals with the description of the relaxation and retardation (so-called creep behavior) of textile yarns, which can be recorded after the first day under constant load. This effect describes the "typical" creep deformation as seen in Fig. (2). The aim is the development of a rheological model, which describes the long-term behavior of the given material by means of $\sigma$ - $\varepsilon$-relations.
However, deformation that occurs immediately after the initial stress application should be handled separately. This effect cannot be labeled as creeping per se, but rather is this the result of the rearranging of the disordered filaments along the tensile axis, leading in turn to a stretching in the length of the fibers. This phenomenon leads to local stress peaks in the individual filaments, that can reach their failure strength and lead to individual filament ruptures. The result is a degraded cross-section and under the same tensile loads, the filament stress increases and consequently also the strain increases.

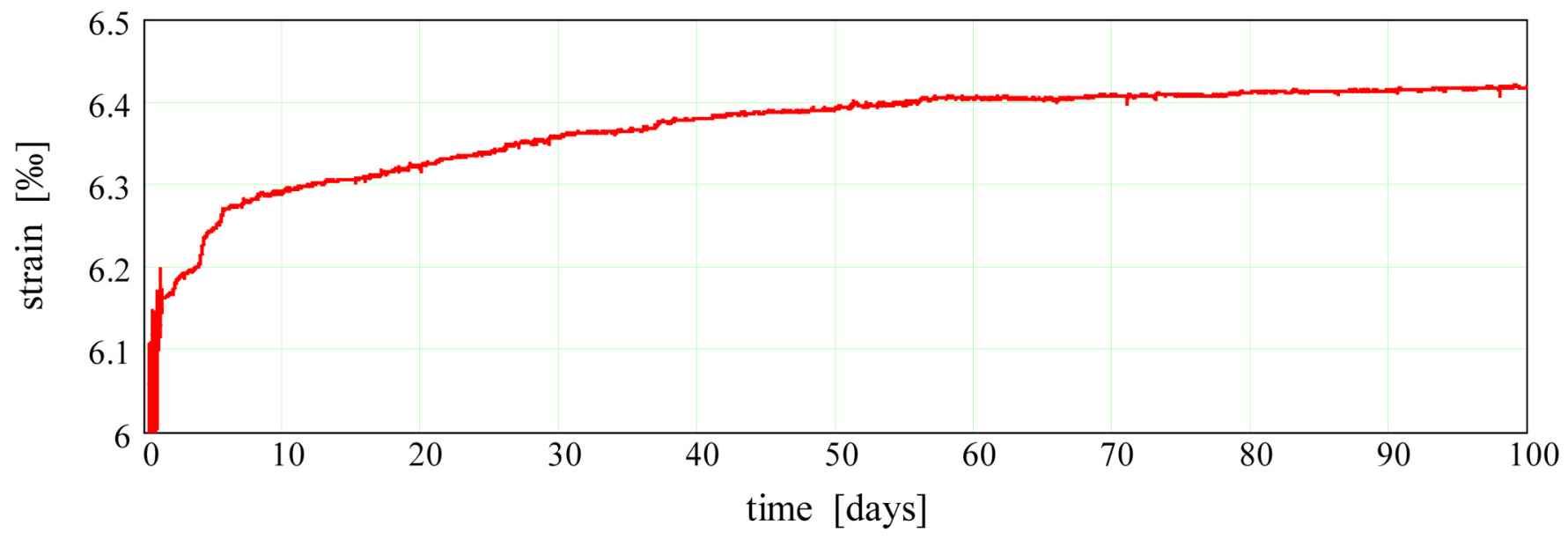

Fig. (2). Strain-time relation of a AR-glass filament yarn, density 640 tex $(=640 \mathrm{~g} / \mathrm{km})$ under $100 \mathrm{~N}$ constant load (Vetrotex / Cem-FIL ${ }^{\circledR}$ ARglass fibers). 
The immediate strain after load application increases according to the load level and the initial length of the stretched yarn. This effect is also known as the decreasing survival probability of individual filaments, see e.g. [12].

Deformations that do not occur immediately after applying force, but rather a few hours after application, are due to the chemical composition of the fibers, specifically their sizing. By coating the filaments with appropriate polymer dispersions, a viscous covering is placed around the fibers. After loads are applied, further strain resulting from the realignment of the filaments must first overcome the resistance of this coating, which accounts for the time delay and is dependent on the composition of the dispersion [13]. Further experiments must be performed before more detailed statements can be made. An additional coefficient is introduced to capture the deformation of the roving due to filament rearrangements according to the experimental measurements.

Although most experiments have concentrated on creep behavior of the fibers under service loads, extensive preliminary experiments of fracture behavior have been conducted. These experiments proved that the breaking strength of the examined glass and carbon filament yarns was, in addition to other factors, highly dependent on the yarn length. The experimental results can be taken from Fig. (3) for AR-glass filament yarn. The diagram shows how the breaking strength decreases with increased yarn length. The cause lies in local failures of individual highly stressed filaments. As a result, the survival probability of the filaments as a whole declines with increasing yarn length, in other words the mean breaking strength of the yarn decreases.

Suitable stress levels are of major importance for future experiments regarding long-term behavior with respect to creep strains. Stress levels should be chosen according to common service load levels, generally to maximal 60 to $70 \%$ of the breaking loads. The results from the above experiments provide a good basis to estimate relevant parameters.

\section{MODELING}

The creep behavior observed in the experiments essentially corresponds to that of a viscoelastic solid. If the stress level is changed, a time-delayed deformation occurs, which converges to a constant value. This behavior can be described by means of the basic mechanical models of a HOOKEan spring and a NEWTONian dashpot, as shown in Table 1, cp. [14] or [15].

Practically all creep characteristics can be modeled by combining the basic elements of a spring and a dashpot. However, before a material model can be constructed, creep behavior must be further defined and various parts must be handled separately.

The first part is classified as the instantaneous behavior of the material. This directly occurring strain $\varepsilon_{\mathrm{el}}$ is described by the YounG's modulus of the glass fibers.

The long-term behavior is distinguished by the following two parts [16]:

- Viscose strain $\varepsilon_{\mathrm{fl}}$; the irreversible strain of the creep deformation, which does not return to the initial value after recovery. Viscose deformations permanently increase over time or gradually die out to reach an ultimate value. In the material model, one or more dashpots capture viscose deformations, which can be equipped with a time ageing function.

- $\quad$ Delayed elastic strain $\varepsilon_{\mathrm{cr}}$; this describes the elastic strain of the material's behavior, that does not take

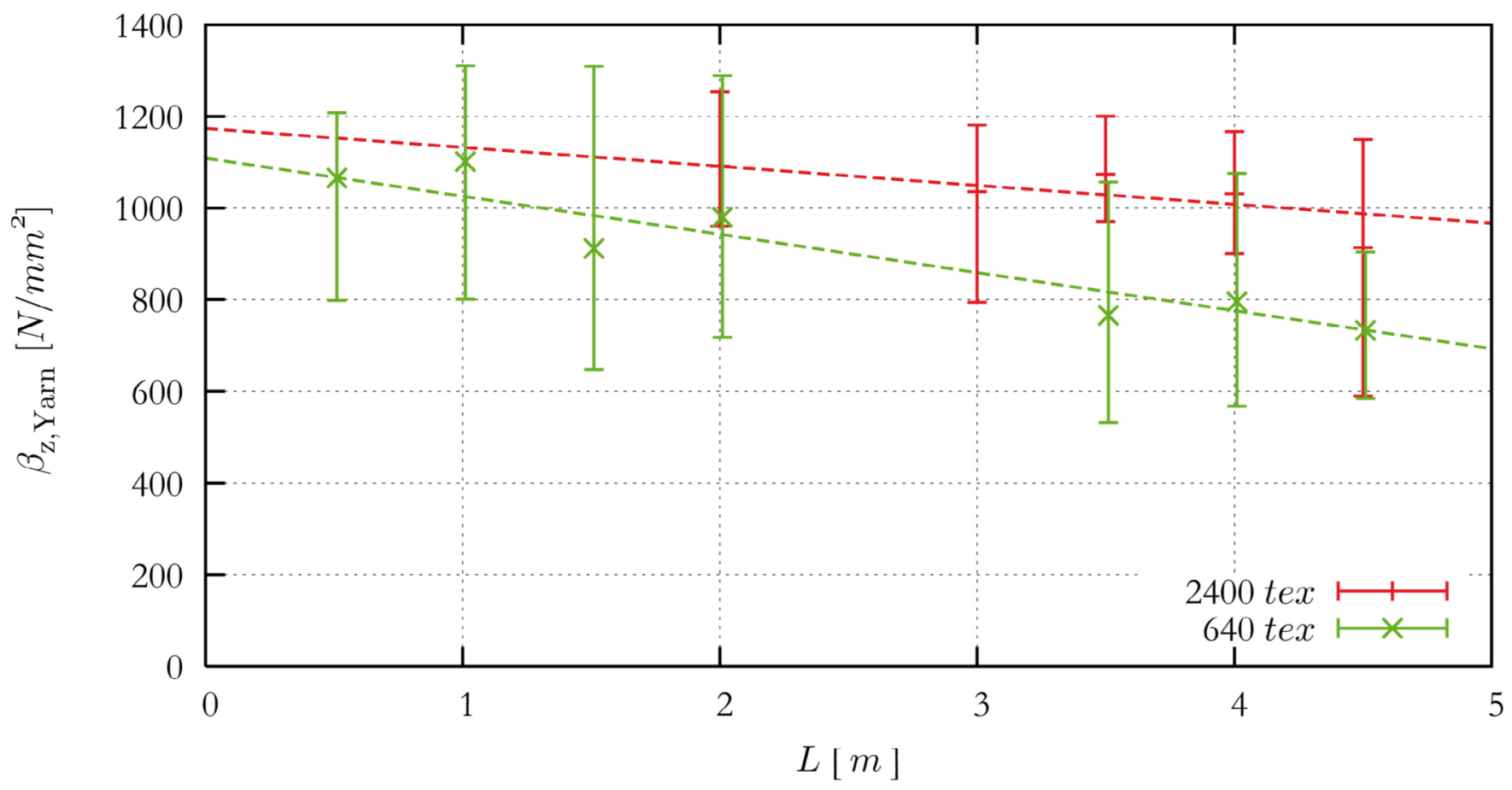

Fig. (3). Influence of yarn length $L$ on the mean breaking strength $\beta_{z, \text { Yarn }}$ of AR-glass filament yarns. 
Table 1. Mechanical Elements Describing Viscoelastic Material Behavior

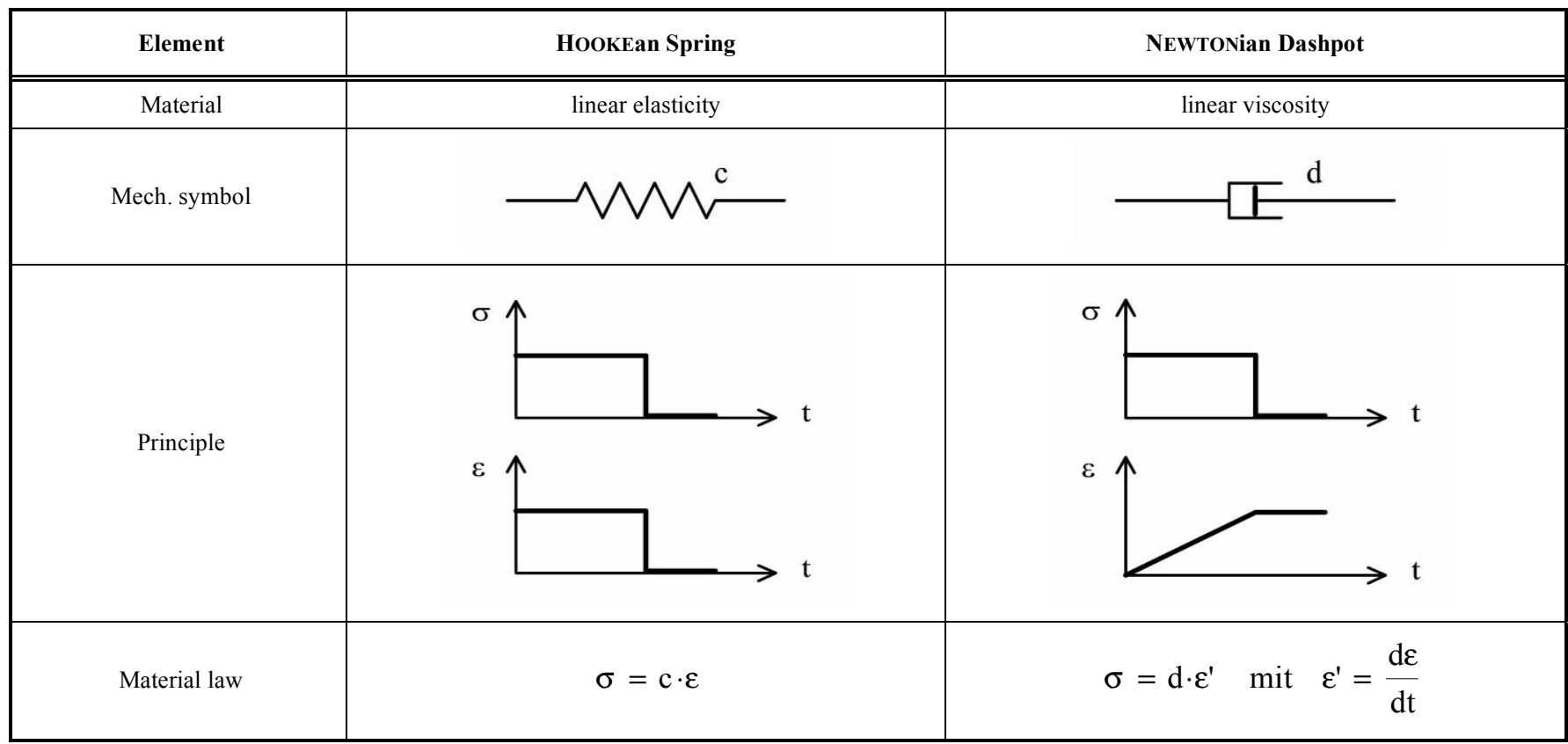

place immediately after stress application, but rather a deformation appears after a delayed period of time. After releasing the stress, the deformation - also timedelayed - recovers and returns to its initial value. As a component in the material model, a parallel setting of a spring and dashpot records the delayed elastic deformation, whereas the "rigidity" of the dashpot determines the length of the time delay.
At this time, it is not possible to determine if the observed creeping of AR-glass fiber yarn contains a viscose phase or not. To determine this, further studies are necessary with changing stress levels and specifically with a complete release of all stress so that the creep recovery curve can be observed over a longer period of time (several months). After considering the present results, a model was chosen which principally includes all possible phases of deformation over a given period of time.

Table 2. Rheological Models Used to Analyze Time Dependent Material Behavior

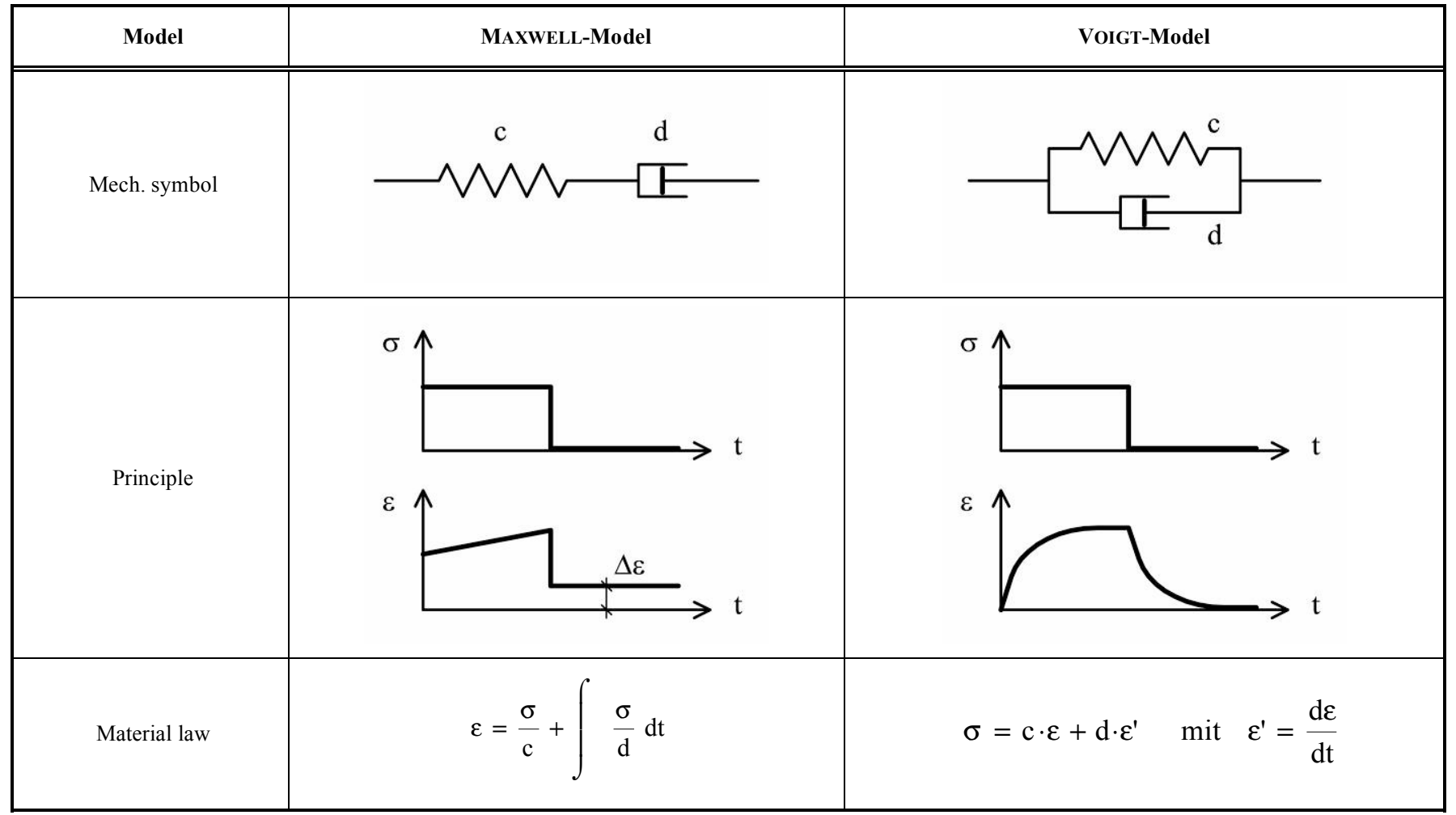


The classical models of a viscous dashpot and an elastic spring are utilized to describe the rates of deformation with respect to time as seen in the rheological models below in Table 2, cp. [17].

These models can be arbitrarily combined, for example to a HoOKe-VoigT-Model (Fig. 4a) or to a MAXWELL-VOIGTModel (Fig. 4b). The MAXWELL-VoIGT-Model is also known as BURGER's Model, and is the model employed for our observations at the start of the test since it contains all deformation phases - instantaneous, jump-like, purely elastic behavior, purely viscous deformation and a delayed elastic deformation. Depending on the desired accuracy further VOIGT components can be added to adjust the delay of the time-dependent strain in the scales of minutes, hours, days or months by means of the rigidity of the dashpots.

\section{MATERIAL LAWS}

Depending on the chosen model, the equations are to be defined in the form of a $\sigma$ - $\varepsilon$-t-relationship. Generally, an equation to show the deformation is formed by adding each component with its individual partial definition, as shown in Eq. 1 for the MaXwell-Voigt-Model in Fig. (4). Further spring-dashpot combinations can be added to this summation [18].

$$
\varepsilon_{\mathrm{ges}}=\sum_{\mathrm{n}} \varepsilon_{\mathrm{n}}=\varepsilon_{\mathrm{el}}+\varepsilon_{\mathrm{fl}}+\sum_{\mathrm{i}} \varepsilon_{\mathrm{cr} . \mathrm{i}}
$$

As long as all spring and dashpot parameters are constants, a linear differential equation in the form of can be derived, where all $a_{i}$ and $b_{j}$ are constant coefficients. If this is not the case, or if the material model consists of many individual components, a closed mathematical solution is not possible or is extremely complicated. For practical purposes a numerical integration was chosen.

$$
\begin{aligned}
& \mathrm{a}_{0} \cdot \sigma+\mathrm{a}_{1} \cdot \sigma^{\prime}+\mathrm{a}_{2} \cdot \sigma^{\prime \prime}+\ldots .+\mathrm{a}_{\mathrm{n}} \cdot \sigma^{(\mathrm{n})} \\
& =\mathrm{b}_{0} \cdot \varepsilon+\mathrm{b}_{1} \cdot \varepsilon^{\prime}+\mathrm{b}_{2} \cdot \varepsilon^{\prime \prime}+\ldots .+\mathrm{b}_{\mathrm{n}} \cdot \varepsilon^{(\mathrm{n})}
\end{aligned}
$$

The basis for the numerical solution are the known state variables at a given time $t_{x}$. Hence, at the point in time $t_{x}$ the stress and strain is known, including all partial stress and strain values for all elements of the material model. Based on this, a small time interval $\Delta \mathrm{t}$ for the stress and strain conditions can be defined for a further point in time $t_{x+1}=t_{x}$ $+\Delta$ t. To accomplish this all parts are considered separately.
Elastic $\quad \varepsilon_{\mathrm{el}}=\mathrm{c}_{\mathrm{el}} \cdot \sigma$

Phase:

With a time constant

YOUNG's modulus $=\mathrm{c}_{\mathrm{el}}$

$\begin{aligned} & \text { Viscous } \\ & \text { Deformation }\end{aligned} \quad \sigma(\mathrm{t})=\mathrm{d}_{\mathrm{F}}(\mathrm{t}) \cdot \varepsilon^{\prime} \mathrm{fl}(\mathrm{t}) \quad$ with $\quad \mathrm{d}_{\mathrm{F}}(\mathrm{t})=\mathrm{a} \cdot \mathrm{e}^{\mathrm{b} \cdot \mathrm{t}}$

Phase:

(with ageing

dashpot

$\varepsilon_{\mathrm{fl}}(\mathrm{t})=\frac{1}{\mathrm{a}} \cdot \int_{\tau=\mathrm{t}_{0}}^{\mathrm{t}} \mathrm{e}^{-\mathrm{b} \cdot \tau} \cdot \sigma(\tau) \mathrm{d} \tau$

parameters)

$\begin{array}{ll}\begin{array}{l}\text { Delayed } \\ \text { Elastic }\end{array} & \sigma(\mathrm{t})=\mathrm{c}_{\mathrm{i}} \cdot \varepsilon_{\mathrm{i}}(\mathrm{t})+\mathrm{d}_{\mathrm{i}} \cdot \varepsilon_{\mathrm{i}}^{\prime}(\mathrm{t}) \\ \begin{array}{l}\text { Deformation } \\ \text { Phase: }\end{array} & \int_{(\text {with } \mathrm{i}=1,}^{\mathrm{t}} \quad \varepsilon_{\mathrm{i}}(\mathrm{t})=\frac{1}{\mathrm{~d}_{\mathrm{i}}} \cdot \int_{\tau=\mathrm{t}_{0}}^{\frac{-\mathrm{c}_{\mathrm{i}}}{\mathrm{d}_{\mathrm{i}}} \cdot(\mathrm{t}-\tau)} \cdot \sigma(\tau) \mathrm{d} \tau \\ 2, \ldots) & \end{array}$

The integrals for the viscous phase and the delayed elastic deformation including the complete stress history $\sigma(t)$ from the initial point of stress application $t_{0}$ to the actual time t. The next step breaks down the above listed integral equations in "incremental" definitions, for example the observed time period is categorized into a known time period $\mathrm{t}_{0}$ to $\mathrm{t}_{\mathrm{x}}$ and a subsequent newly defined time increment $\Delta \mathrm{t}$ which reaches to the concluding point in time of observation $t_{x+1}$. The solution of this sufficiently small time interval $\Delta t$ is solved by a numerical quadrature.

Basic equation:

$\varepsilon\left(t_{x+1}\right)=\int_{\tau=t_{0}}^{t_{x}} \ldots . d \tau=\int_{\tau=t_{0}}^{t_{x}} \ldots . d \tau+\int_{\tau=t_{x}}^{t_{x}} \ldots .+d \tau=I\left(t_{0}, t_{x}\right)+\int_{\tau=t_{x}}^{t_{x}} \ldots .+d \tau$

The integral function $\mathrm{I}\left(\mathrm{t}_{0}, \mathrm{t}_{\mathrm{x}}\right)$ contains the complete stressstrain history from starting point $t_{0}$ to time $t_{x}$, and is suitable to numerically represent all phases.

After solving the observed time increment $\Delta \mathrm{t}$, the incremental material law for the viscous deformation phase is as follows:

$$
\varepsilon_{f l}\left(t_{x+1}\right)=I_{f l}\left(t_{0}, t_{x}\right)+\frac{1}{a} \cdot\left(e^{-b \cdot t_{x}} \cdot \sigma\left(t_{x}\right)+e^{-b \cdot t_{x+1}} \cdot \sigma\left(t_{x+1}\right)\right) \cdot \frac{\Delta t}{2}
$$

and that for the delayed elastic deformation phase

$$
\varepsilon_{\text {cr.i }}\left(\mathrm{t}_{\mathrm{x}+1}\right)=\mathrm{I}_{\text {cr.i }}\left(\mathrm{t}_{0}, \mathrm{t}_{\mathrm{x}}\right)+\frac{1}{\mathrm{~d}_{\mathrm{i}}} \cdot\left(\mathrm{e}^{\frac{-\mathrm{c}_{\mathrm{i}}}{\mathrm{d}_{\mathrm{i}}} \cdot \Delta \mathrm{t}} \cdot \sigma\left(\mathrm{t}_{\mathrm{x}}\right)+\sigma\left(\mathrm{t}_{\mathrm{x}+1}\right)\right) \cdot \frac{\Delta \mathrm{t}}{2}
$$

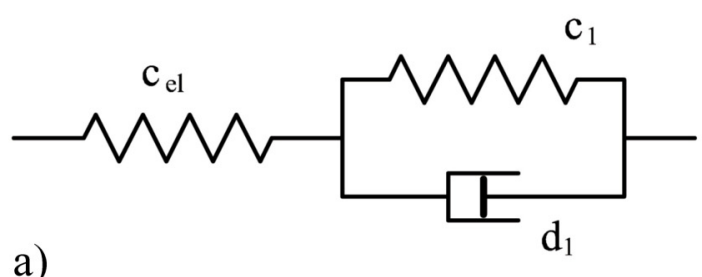

a)

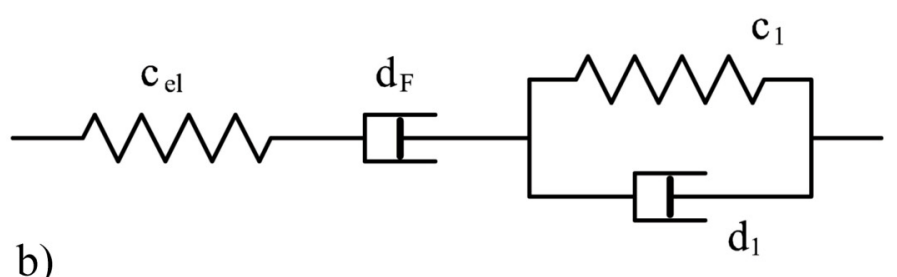

b)

Fig. (4). Some possible spring-dashpot combinations for viscoelastic material models: a) HoOKE-VOIGT-Model. b) MAXWELL-VOIGT-Model. 

follows

After adding all phases, the complete material law is as

$$
\begin{gathered}
\varepsilon\left(\mathrm{t}_{\mathrm{x}+1}\right)=\mathrm{c}_{\mathrm{el}} \cdot \sigma\left(\mathrm{t}_{\mathrm{x}+1}\right)+\mathrm{I}_{\mathrm{fl}}\left(\mathrm{t}_{0}, \mathrm{t}_{\mathrm{x}}\right)+\frac{1}{\mathrm{a}} \cdot\left(\mathrm{e}^{-\mathrm{b} \cdot \mathrm{t}_{\mathrm{x}}} \cdot \sigma\left(\mathrm{t}_{\mathrm{x}}\right)+\mathrm{e}^{-\mathrm{b} \cdot \mathrm{t}_{\mathrm{x}+1}} \cdot \sigma\left(\mathrm{t}_{\mathrm{x}+1}\right)\right) \cdot \frac{\Delta \mathrm{t}}{2} \\
\ldots .+\sum_{\mathrm{i}}\left[\mathrm{I}_{\text {cr.i }}\left(\mathrm{t}_{0}, \mathrm{t}_{\mathrm{x}}\right)+\frac{1}{\mathrm{~d}_{\mathrm{i}}} \cdot\left(\mathrm{e}^{\frac{-\mathrm{c}_{\mathrm{i}}}{\mathrm{d}_{\mathrm{i}}} \cdot \Delta \mathrm{t}} \cdot \sigma\left(\mathrm{t}_{\mathrm{x}}\right)+\sigma\left(\mathrm{t}_{\mathrm{x}+1}\right)\right) \cdot \frac{\Delta \mathrm{t}}{2}\right]
\end{gathered}
$$

with $\varepsilon\left(t_{x+1}\right)$ and $\sigma\left(t_{x+1}\right)$ as variables to be determined. If all known and constant values at the time $t_{x}$ are combined to create a cumulative expression $\mathrm{G}\left(\mathrm{t}_{\mathrm{x}}\right)$, and all values at time $t_{x+1}$ to create $K\left(t_{x+1}\right)$, then the material law can be written in a more manageable form. It can be written in terms of $\varepsilon=\mathrm{f}(\sigma, \mathrm{t})$ or $\sigma=\mathrm{f}(\varepsilon, \mathrm{t})$ :

$$
\begin{aligned}
& \varepsilon\left(\mathrm{t}_{\mathrm{x}+1}\right)=\mathrm{I}_{\mathrm{fl}}\left(\mathrm{t}_{0}, \mathrm{t}_{\mathrm{x}}\right)+\sum_{\mathrm{i}} \mathrm{I}_{\text {cr.i }}\left(\mathrm{t}_{0}, \mathrm{t}_{\mathrm{x}}\right)+\mathrm{G}\left(\mathrm{t}_{\mathrm{x}}\right) \cdot \sigma\left(\mathrm{t}_{\mathrm{x}}\right)+\mathrm{K}\left(\mathrm{t}_{\mathrm{x}+1}\right) \cdot \sigma\left(\mathrm{t}_{\mathrm{x}+1}\right) \\
& \sigma\left(\mathrm{t}_{\mathrm{x}+1}\right)=\frac{1}{\mathrm{~K}\left(\mathrm{t}_{\mathrm{x}+1}\right)} \cdot\left(\varepsilon\left(\mathrm{t}_{\mathrm{x}+1}\right)-\mathrm{I}_{\mathrm{fl}}\left(\mathrm{t}_{0}, \mathrm{t}_{\mathrm{x}}\right)-\sum_{\mathrm{i}} \mathrm{I}_{\text {cr. }}\left(\mathrm{t}_{0}, \mathrm{t}_{\mathrm{x}}\right)-\mathrm{G}\left(\mathrm{t}_{\mathrm{x}}\right) \cdot \sigma\left(\mathrm{t}_{\mathrm{x}}\right)\right)
\end{aligned}
$$

\section{MAPPING THE MEASURED DATA BY MEANS OF A MATERIAL MODEL}

Next it is necessary to map the measured curve with the derived material law and to determine the individual parameters for the spring and dashpot. All experiments were performed under a constant stress level over the whole experiment duration. This means that the amount of the irreversible viscous deformation - if indeed it exists - is not yet known. Therefore no dashpot for the viscous part is added to the model at the moment. A constant stress in the fibers allows a closed-form solution of the constitutive equation.

For each part of the delayed elastic deformation phase, based on the VoIGT-Model (see Table 2), the strain rate under constant stress can be taken from Eq. $5 \mathrm{~b}$ and is given with

$$
\varepsilon_{i}(t)=\frac{1}{c_{i}} \cdot \sigma \cdot\left[1-e^{\frac{-c_{i}}{d_{i}} \cdot\left(t-t_{0}\right)}\right] \quad \text { mit } \quad \sigma=\sigma(t)=\text { konst }
$$

In a model according to Fig. (4) with a spring $\mathrm{c}_{\mathrm{el}}$ (= shortterm YOUNG's-modulus) and $\mathrm{n}$ as subsequent spring-dashpot units $c_{i}$ and $d_{i}$, the total deformation can be calculated as $\varepsilon_{\text {ges }}(\mathrm{t})=\varepsilon(\mathrm{t})$ :

$$
\varepsilon(t)=\frac{\sigma}{c_{e l}}+\sum_{i} \frac{1}{c_{i}} \cdot \sigma \cdot\left[1-e^{\frac{-c_{i}}{d_{i}} \cdot\left(t-t_{0}\right)}\right] \quad \text { für } \quad i=1 \ldots n
$$

Explanatory note on the instantaneous elastic deformation on the spring $\mathrm{c}_{\mathrm{el}}$ :

As mentioned at the beginning, all experiments showed a significant deformation within the first few hours after applying load, which cannot be defined as creep motion. Based on the size of this deformation, the glass fiber YOUNG's-modulus was reduced by a corrective factor $v_{k}$ :

$$
c_{e l}=\frac{E}{\left(1+v_{k}\right)}
$$

Therefore the observation of the creep behavior relates to the following time response, in other words $\mathrm{t}_{0} \approx 1$ day.

The starting point for the following observations was taken from the long-term tension experiment on AR-glass filament yarns as depicted in Fig. (2). All relevant values and conditions for the used yarn are given in Table 3.

Table 3. Material Properties and Conditions of the Used Yarn for the Long-Term Tension Experiment

\begin{tabular}{|c|c|}
\hline \multicolumn{2}{|c|}{ AR-Glass Fiber Yarn Values Under Long-Term Tensile Forces } \\
\hline \hline Yarn titer; cross-section area & 640 tex $\rightarrow \mathrm{A}=0,25 \mathrm{~mm}^{2}$ \\
\hline Length of hanging yarn & $1=26 \mathrm{~m}$ \\
\hline Applied load & $\mathrm{F}=10 \mathrm{kP}=100 \mathrm{~N}$ \\
\hline YOuNG's -Modulus glass fibers & $\mathrm{E}=70.000 \mathrm{~N} / \mathrm{mm}^{2}$ \\
\hline Observed time period & $\mathrm{t}=106$ days \\
\hline
\end{tabular}

The identification of the material parameters begins with the spring constant $\mathrm{c}_{\mathrm{el}}$ to describe the short-term behavior. Fig. (5) depicts the instantaneous deformation development, immediately following load application. The spring constant $\mathrm{c}_{\mathrm{el}}$ defines the deformation about 24 hours after the initial jump-like deformation. This was derived in the following manner.

\section{Measured}

deformation after

the initial jump- $\quad \varepsilon_{\text {meas }}=6.15 \%$

like deformation

at the start:

\section{Calculated}

deformation based

on HOOKE's law

and the glass fiber

$$
\varepsilon_{\text {calc }}=\frac{\sigma}{\mathrm{E}}=\frac{\mathrm{F}}{\mathrm{A} \cdot \mathrm{E}}=\frac{100}{0.25 \cdot 70000}=5.72 \%
$$

YOUNG's-

modulus:

Difference $\rightarrow$ corrective factor:

$$
\begin{aligned}
& \frac{\varepsilon_{\text {meas }}}{\varepsilon_{\text {calc }}}=\frac{6.15}{5.72}=1.075 \rightarrow v_{\mathrm{k}}=7.5 \% \\
& \mathrm{c}_{\mathrm{el}}=\frac{70000}{(1+0.075)}=65120 \mathrm{~N} / \mathrm{mm}^{2}
\end{aligned}
$$$$
\text { Modified spring }
$$$$
\text { constant } \mathrm{c}_{\mathrm{el}} \text { : }
$$

For the following creep observations utilizing the model from Fig. (4a) (HoOKE-VOIGT-model), we examined how many subsequent spring-dashpot units were necessary or useful in order to describe a deformation as close to reality as possible. Four variations with one to four VoIGT-units were considered. The spring-dashpot constants were evaluated by comparing their parameters. The curves are depicted in Figs. (6-9). 


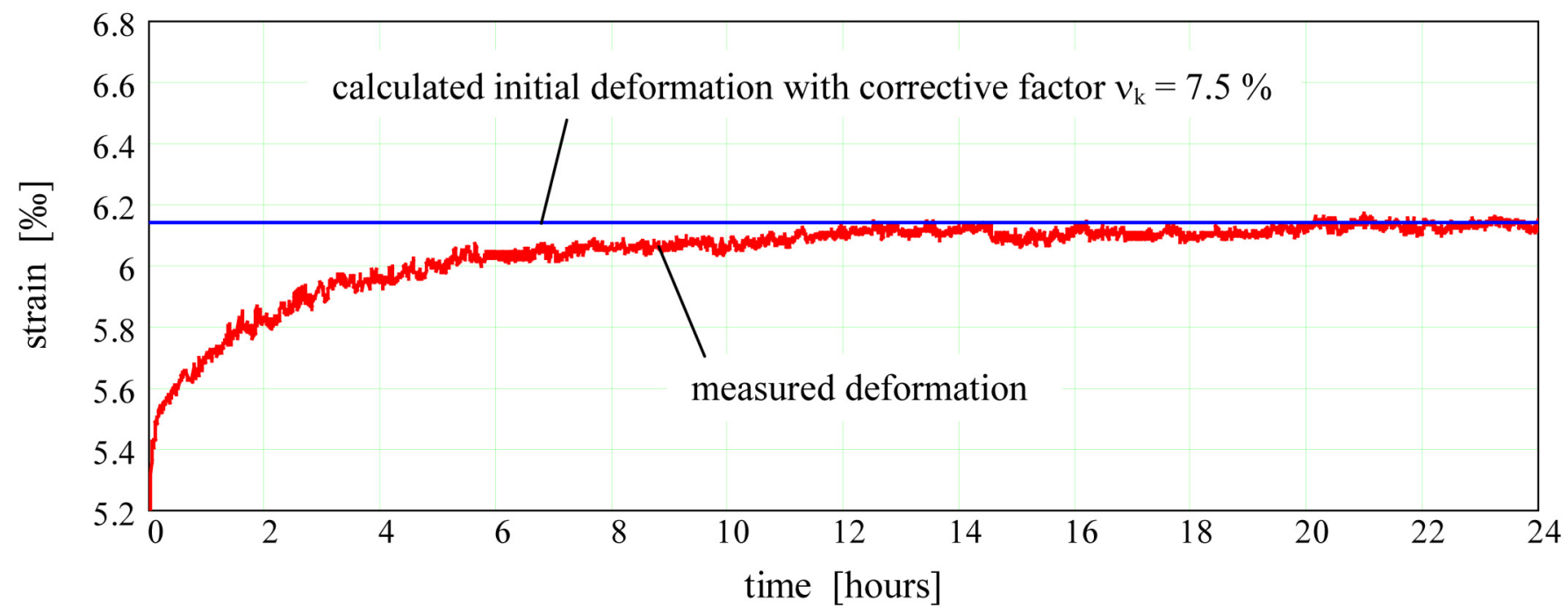

Fig. (5). Development of yarn deformation (strain) in the beginning stages (first day).

According to the material model, all subsequent springs virtually result in the "effective YouNG's modulus" reached at the end of creep deformation. Each dashpot offers the opportunity to control the time delay of the effects of the individual springs. One spring-dashpot unit offers only a rough approximation of the measured curve (Fig. 6), whereas already with two spring-dashpot units a relatively good approximation of the measured values is achieved (Fig. 7). For most of the practical calculations, the accuracy of this curve is adequate. With each additional spring-dashpot unit, the deformation comes within closer approximation of the actual measured relation (Figs. 8, 9). However, it should be considered if the improved quality of the material model is worth the increased calculation effort.

For our further observations within the framework of this paper, we utilized a HOOKE-VOIGT-model with a linear, elastic spring and two subsequent spring-dashpot units according to Table 5 for the time interval of the delayed elastic deformation.
Table 4. Spring and Dashpot Parameters for the Material Model with One Spring-Dashpot Unit

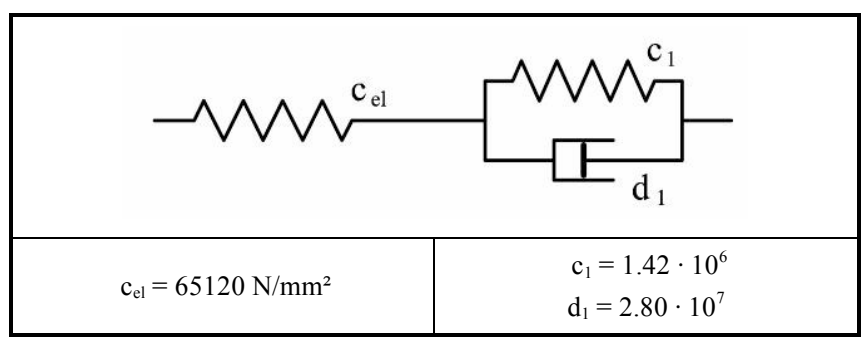

\section{UTILIZING THE MATERIAL MODEL FOR PRACTICAL CALCULATIONS}

After defining a suitable model and material parameters, a $\sigma$ - $\varepsilon$-t-relationship is available to calculate the long-term behavior of the textile fibers with respect to various stresstime scenarios, as well as its usage for calculation models for composite materials such as textile reinforced concrete. The

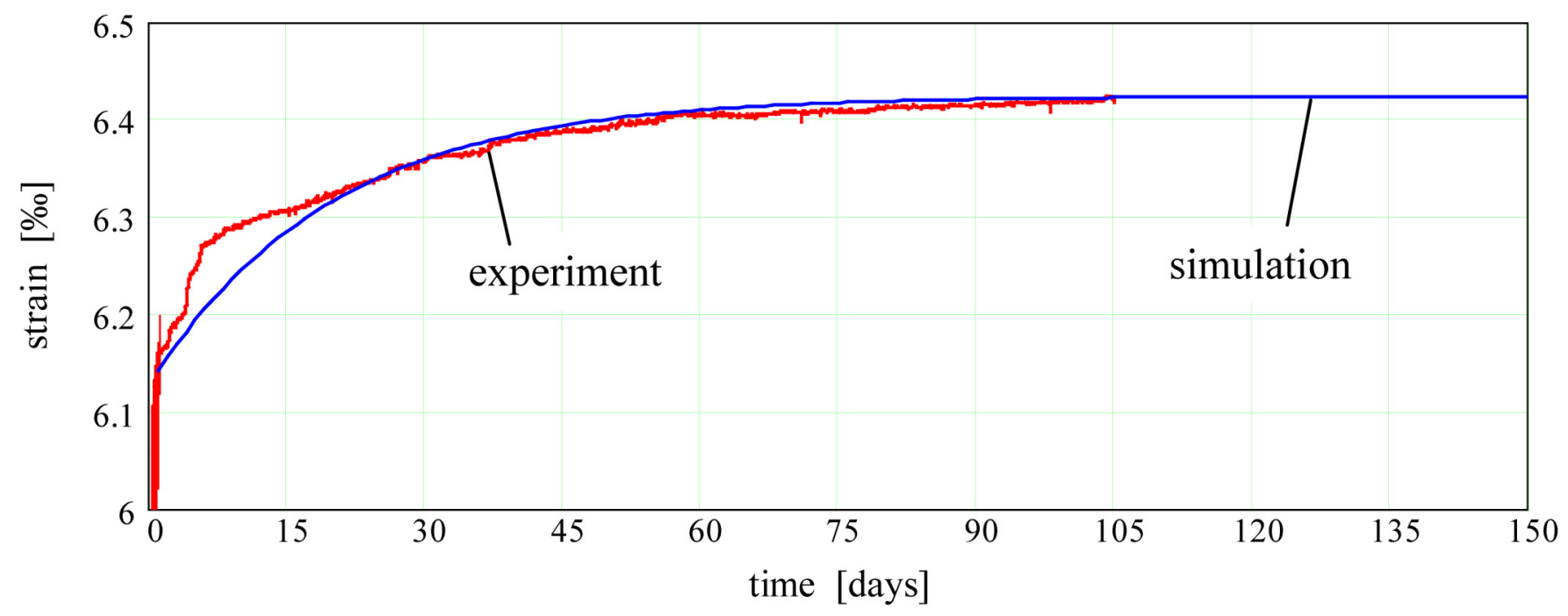

Fig. (6). Map of the time-dependent deformation development with material model from Table 4. 
Table 5. Spring and Dashpot Parameters for the Material Model with Two Spring-Dashpot Units

\begin{tabular}{l|l|l|}
$\mathrm{c}_{\mathrm{el}}=65.120 \mathrm{~N} / \mathrm{mm}^{2}$ & $\begin{array}{c}\mathrm{c}_{1}=2,50 \cdot 10^{6} \\
\mathrm{~d}_{1}=7,70 \cdot 10^{7}\end{array}$ \\
$\mathrm{c}_{2}=3,30 \cdot 10^{6}$ \\
$\mathrm{~d}_{2}=2,10 \cdot 10^{7}$
\end{tabular}

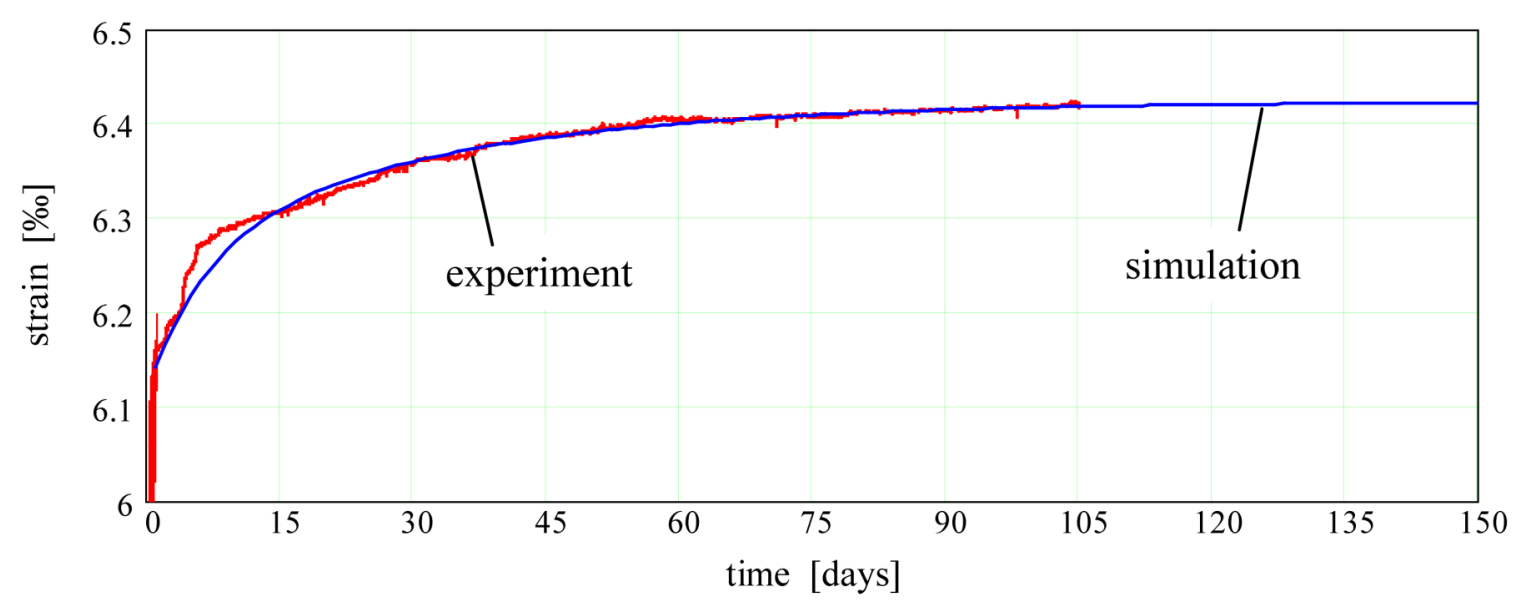

Fig. (7). Map of the time-dependent deformation development with material model from Table 5.

Table 6. Spring and Dashpot Parameters for the Material Model with Three Spring-Dashpot Units

\begin{tabular}{|l|c|c|c|}
\hline \multicolumn{2}{|c|}{$\mathrm{c}_{\mathrm{el}}=65.120 \mathrm{~N} / \mathrm{mm}^{2}$} & $\begin{array}{c}\mathrm{c}_{1}=4,10 \cdot 10^{6} \\
\mathrm{~d}_{1}=1,18 \cdot 10^{8}\end{array}$ & $\begin{array}{c}\mathrm{c}_{2}=3,60 \cdot 10^{6} \\
\mathrm{~d}_{2}=7,10 \cdot 10^{7}\end{array}$ \\
$\mathrm{~d}_{3}=8,20 \cdot 10^{6}$
\end{tabular}

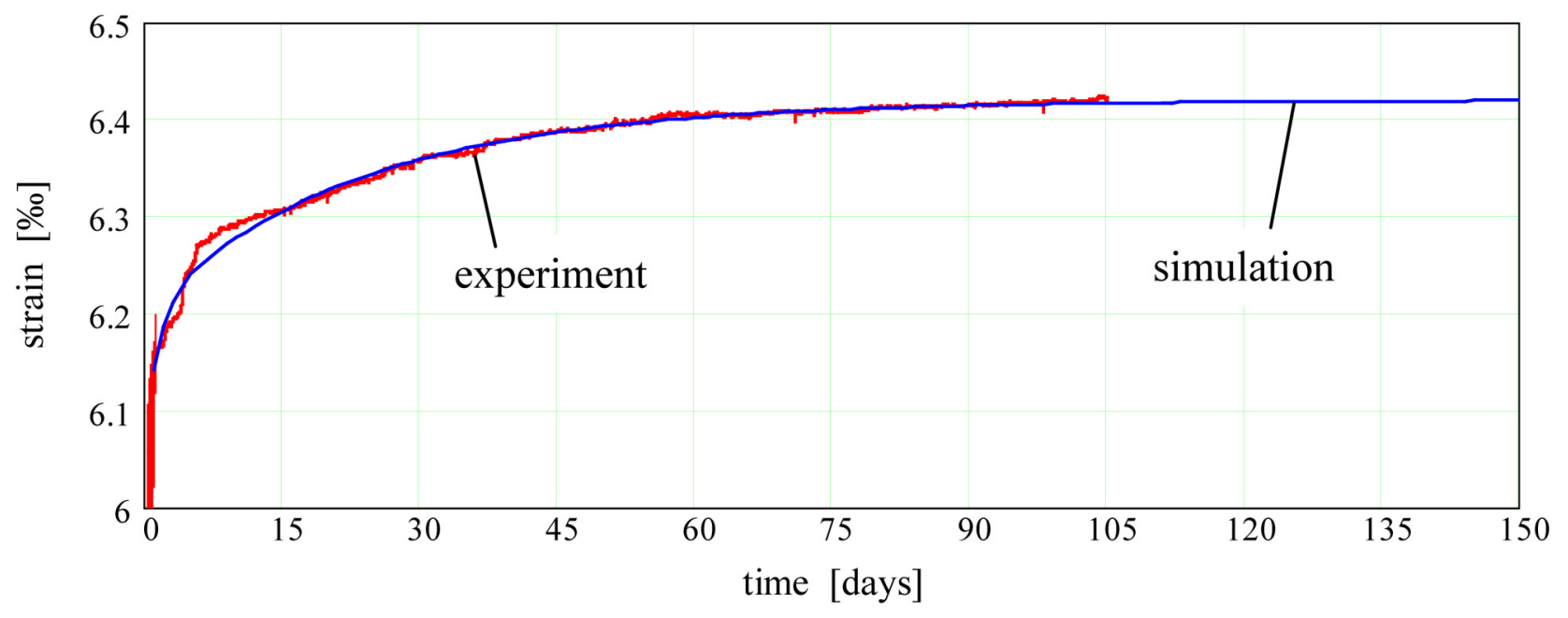

Fig. (8). Map of the time-dependent deformation development with material model from Table 6.

next step examined the behavior of the fibers only. For our experiment, the material law as derived above from the
HoOKE-VOIGT-model with two spring-dashpot units in series and their parameters was implemented, as seen in Table $\mathbf{5 .}$ 
Table 7. Spring and Dashpot Parameters for the Material Model with Four Spring-Dashpot Units

\begin{tabular}{|l|l|l|l|l|}
\hline $\mathrm{c}_{\mathrm{el}}=65.120 \mathrm{~N} / \mathrm{mm}^{2}$ & $\begin{array}{c}\mathrm{c}_{1}=4,30 \cdot 10^{6} \\
\mathrm{~d}_{1}=1,80 \cdot 10^{8}\end{array}$ & $\begin{array}{c}\mathrm{c}_{2}=3,60 \cdot 10^{6} \\
\mathrm{~d}_{2}=7,10 \cdot 10^{7}\end{array}$ & $\begin{array}{c}\mathrm{c}_{3}=8,20 \cdot 10^{6} \\
\mathrm{~d}_{3}=1,60 \cdot 10^{7}\end{array}$ \\
$\begin{array}{c}\mathrm{c}_{4}=1,20 \cdot 10^{7} \\
\mathrm{~d}_{4}=8,30 \cdot 10^{6}\end{array}$ \\
$\mathrm{~d}_{1}$
\end{tabular}

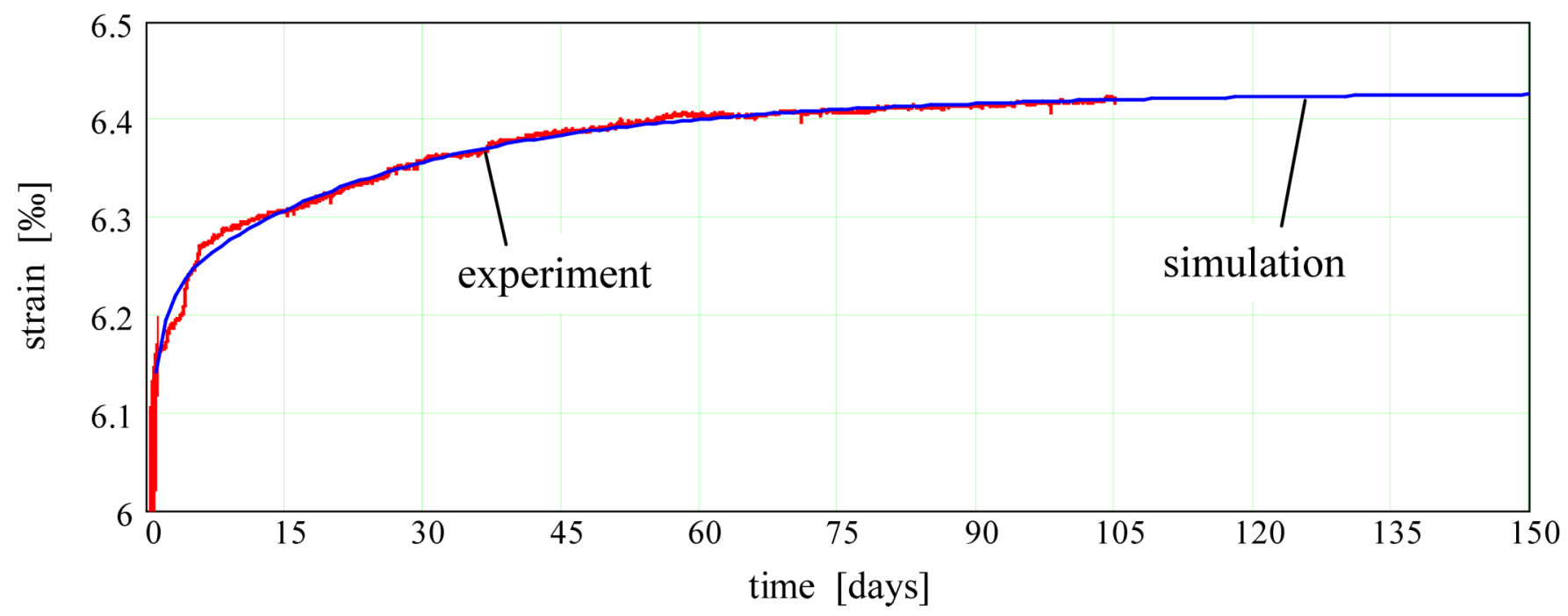

Fig. (9). Map of the time-dependent deformation development with material model from Table 7.

Under constant loads, Eq. 13 offers a closed-formed $\sigma-\varepsilon$ t-relationship, where the strain directly results from the stress for each time point $t$. When constant stress levels act in several time periods, Eq. 13 can also be applied to each period. Each individual spring-dashpot unit's material model can be split-up by

$$
\varepsilon_{i}(t)=\frac{1}{d_{i}} \cdot \int_{\tau=t_{0}}^{t} e^{\frac{-c_{i}}{d_{i}} \cdot(t-\tau)} \cdot \sigma(\tau) d \tau=\sum_{k=1}^{n} \frac{1}{d_{i}} \cdot \sigma_{k} \cdot \int_{\tau=t_{k}-1}^{t_{k}} e^{\frac{-c_{i}}{d_{i}} \cdot(t-\tau)} d \tau
$$

where $\mathrm{n}$ is the number of the individual time periods, and $\sigma_{\mathrm{k}}$ defines the time periods and their comparable constant stress level.

The creep curve under the following simulated stress levels for the AR-glass filament yarn depicted in Fig. (7) (evaluated for 105 days) can be further extrapolated as such:

- $\quad$ when $\mathrm{t}_{0}=0$, force with constant stress $\sigma_{1}=400 \mathrm{~N} / \mathrm{mm}^{2}$,

- $\quad$ at $\mathrm{t}_{1}=150$ days, stress release in first stage at $\sigma_{2}=300 \mathrm{~N} / \mathrm{mm}^{2}$,

- $\quad$ at $\mathrm{t}_{2}=250$ days, stress release in stage two at $\sigma_{3}=200 \mathrm{~N} / \mathrm{mm}^{2}$.

As expected, after each stress release a time-delayed creep relaxation phase followed, largely determined by the stress difference from the previous stage. Analogous to the magnitude of the creep deformation in relation to the whole strain deformation, the creep relaxation plays a minor role, as seen in Fig. (10). The relaxation time rate of the delayed elastic deformation after stress release correlates to that characteristic in the material model after load application.

\section{COMPARING THE ATTAINED EXPERIMENTAL RESULTS}

Within the framework of present resources only a few individual experiments could be realized. However, these results prove that long-term stress over a given period of time causes increases in filament strain due to creep. The measured experimental values show a small scattering.

Fig. (11) depicts the measured creep curve in the beginning stages of few experiments; all realized with 640 tex AR-glass filament yarns and different stress loads. The yarns were taken from various spools. The deformations in the beginning stages are clearly recognizable. In all cases the same magnitude about 5 to $10 \%$ of the initial elastic strain due to the filament rearrangement within the yarn was reached after the first day.

All measured creep strains are in the magnitude of 3 to $5 \%$ in relation to the elastic strain. Also, the response in time is similar in all cases. For the material model from Table 5 the spring-dashpot parameters were calibrated for one of the experiments. With this parameter set the creep strain relations were compared with four other experiments. The results are similar with little deviance from the calculated 


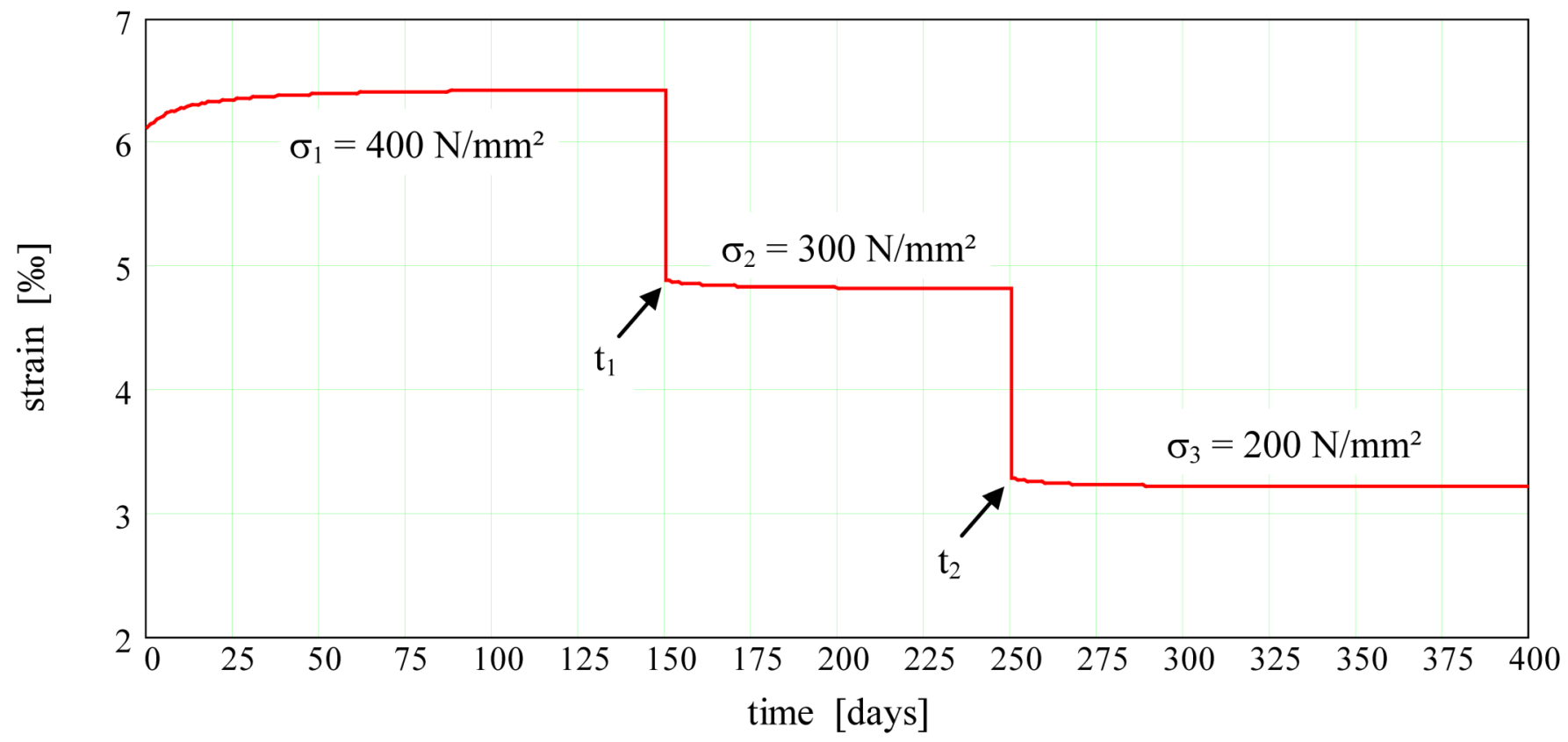

Fig. (10). Calculation of strain in a AR-glass filament yarn under three stress levels.

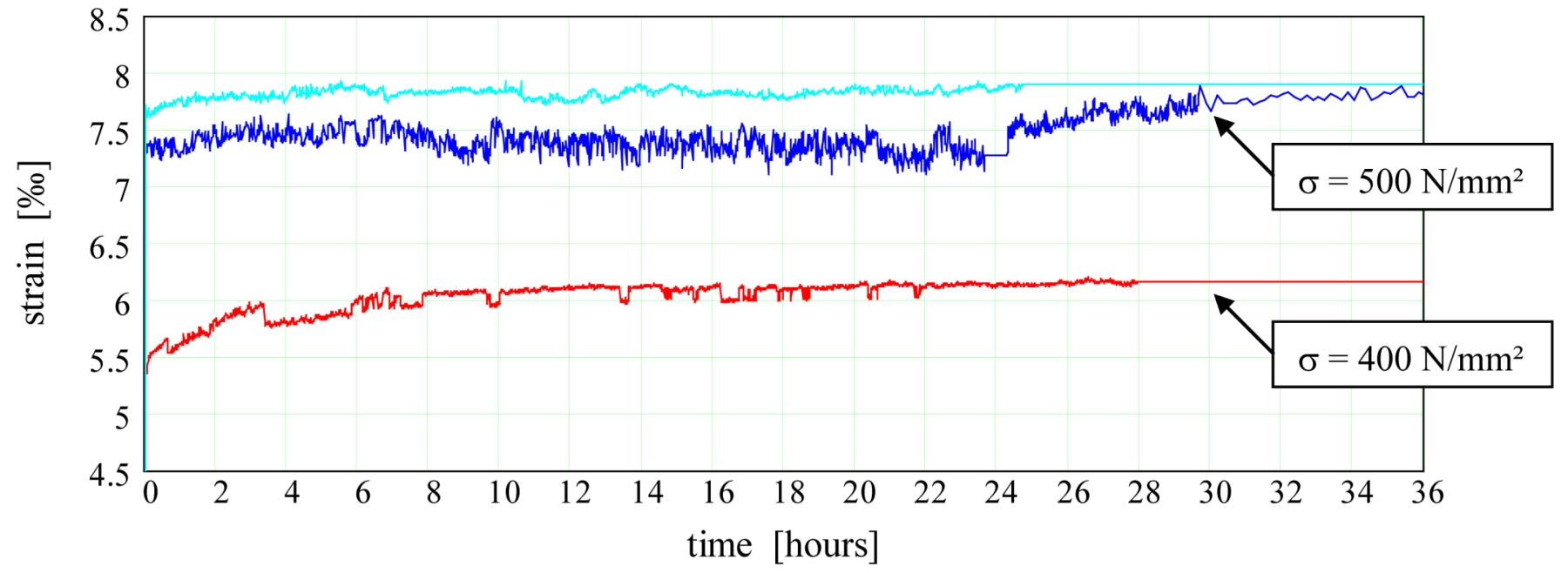

Fig. (11). Experimental measured strains in the first 36 hours after load application; comparison of various glass fiber yarns all of a yarn titer of 640 tex under different stress levels.

creep curve. Fig. (12) shows the results of two experiments, which were realized over a period of about 100 days.

\section{REMARKS ON THE PLANNED EXPERIMENTAL METHODS}

In order to examine the creep recovery behavior and the permanent strain of the yarns remaining after the removal of loads, it was necessary to technically modify the standard test method used for examining the effects of continuous loads (Fig. 13). In the present form the standard method is suitable for long-term measurements with constant stress loads. To ensure precise measurements with a tolerance of 1 $\mu \mathrm{m}$, the experimental area is temperature regulated and protected from general disturbances.

Up to six yarn samples can be simultaneously and independently tested thanks to a modular configuration system. All standard thread clamps can be mounted in one test station. However, to measure the strain by means of the clamp mounts, the yarn samples must be inserted completely straight and free of entanglements in a synthetic resin potting situated directly in the clamp mount. Slipping is controlled by means of an in-house designed "slip control mechanism", so that the yarn strain can be recorded with the help of a mechanical gauge indicator which measures the precise movement of the slide mounted clamp. The span of the yarn samples between the clamps is $750 \mathrm{~mm}$. The experimental equipment is schematic illustrated in Fig. (14).

To date, the stress loads were steadily applied by means of mechanical tension until the target load was reached. The speed at which the loads increase remains constant. The applied loads are measured directly with load cells. To accommodate the proposed load changing applications, two additional measuring units must be integrated in the test station. For these two units, loads are applied by servo 

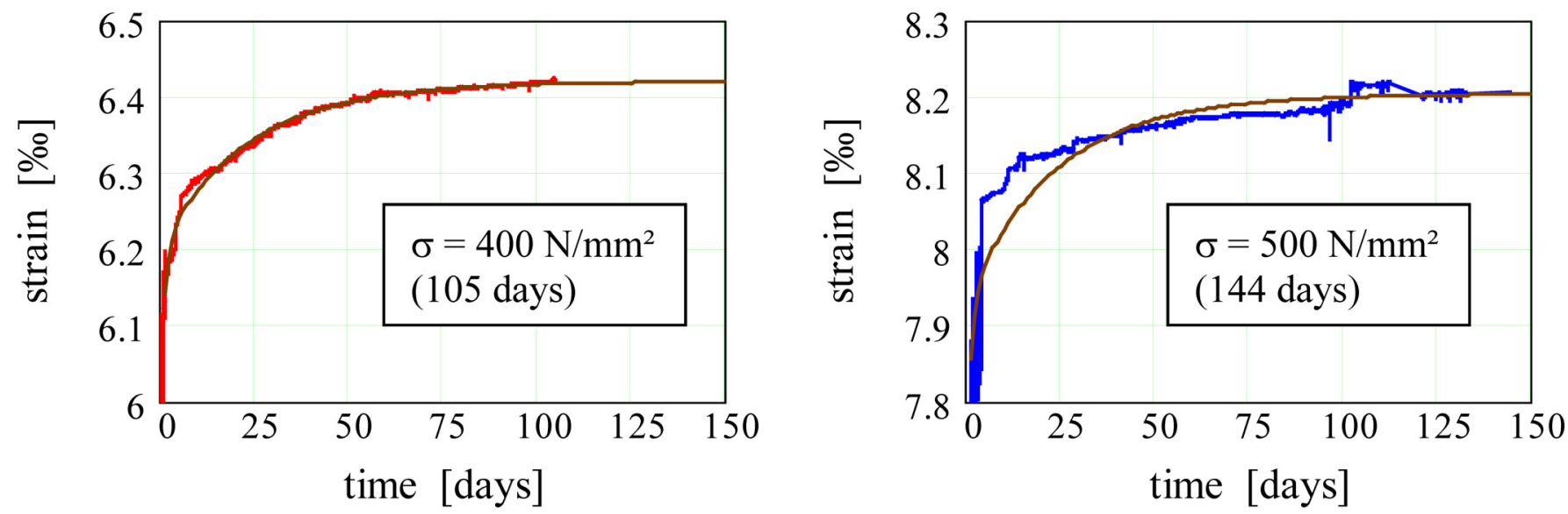

Fig. (12). Comparison of results from experiment and simulation with the material model from Table 6 (measured results and simulated creep curves).
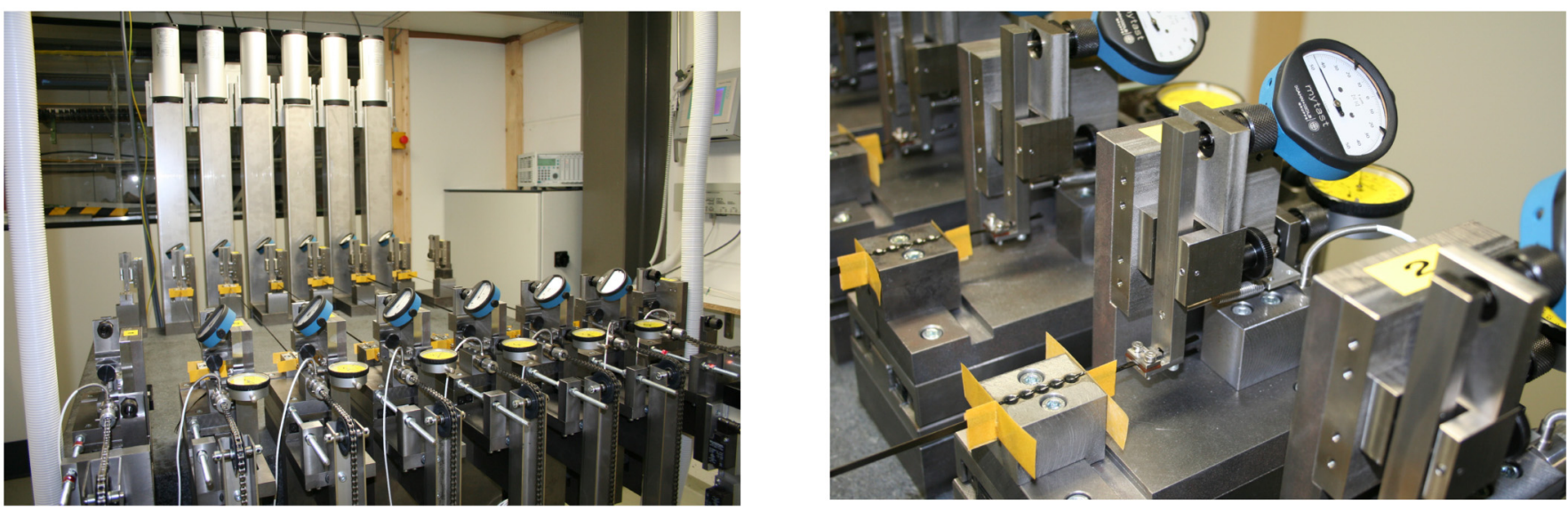

Fig. (13). Test station for semi-static continuous stress on high-performance filament yarn.

motors. The load cycles are given in load - time values, where the load application and its duration can be chosen freely and independently. Additionally, a new incremental length measurement system based on glass measuring sticks is implemented. This new system combined with a sample insert control continually measures the change in thread length.

The experimental results serve as a preliminary verification of the developed rheological prognosis models. Along with AR-glass filament yarns, carbon filament yarns and polymer coated yarns were the focus of the long-term experiments. The fatigue test station is equally suitable to test the above yarns. The goal remains to distinguish the differences between AR-glass filament yarns and carbon or to determine whether the observations of AR-glass behavior can be extrapolated onto that of carbon over longer periods of time from a few weeks to several months.

\section{SUMMARY AND OUTLOOK}

Current long-term experiments realized under constant stress with AR-glass filament yarns clearly show a timedependent material behavior. The magnitude of additional strain over time was up to $5 \%$ in relation to that of the instantaneous elastic strain. This can be relevant for practical purposes. More extensive research is needed to clarify the scale of these findings.
It is possible by using the presented material models, to describe the observed behavior of glass filament yarns mechanically and to quantify them within a framework of given material parameters. With these models, simulations can be calculated with various load-time scenarios. The aim of these experiments is to predetermine the deformation or strain in the yarn itself, leading to the recognition of the interaction of elements in composite building members (i. e. textile reinforced concrete members). Then the appropriate calculation models can be applied to evaluate those construction members.

Within the framework of further experiments on the long-term behavior of textile filament yarns the following aspects should closely be examined and considered:

- Creep behavior should be differentiated into its components consisting of the irreversible viscous deformation and the reversible delayed elastic deformation, which recovers after stress release. To analyze this, it is necessary to perform various experiments with changing stress levels including those with complete stress release. These components can be represented and analyzed separately in the material models.

- In the experiments until now, an increase in strain could be seen immediately after load application. The 


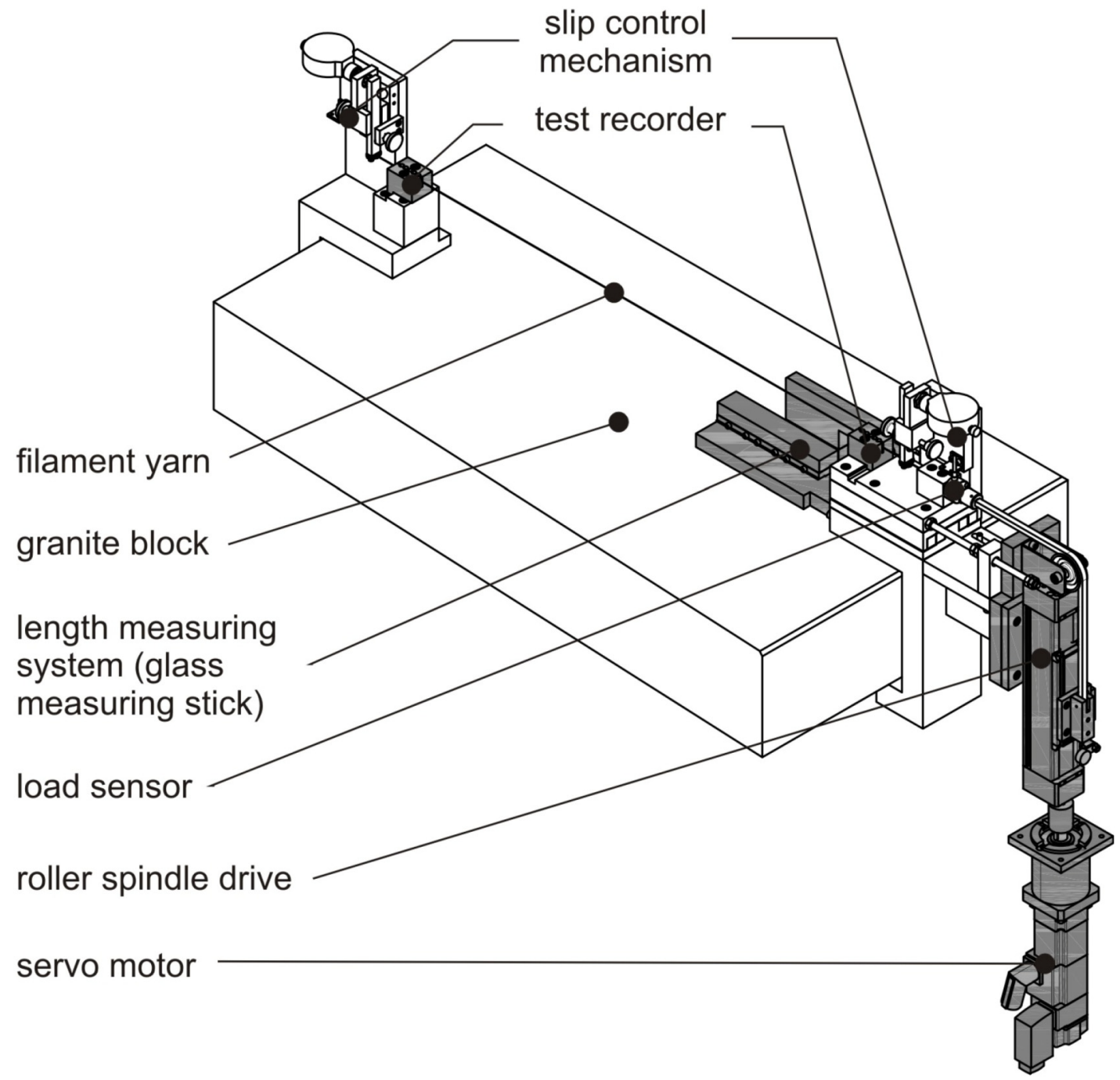

Fig. (14). Modifications to fatigue test station (gray areas) for cyclical tests on thread stressing.

assumed causes (realignment/reorientation of the filaments, individual filament failure and sizing properties) must be more closely examined and clarified if this behavior can be understood as part of creep behavior.

- Environmental influences, such as temperature, humidity, and the alkaline qualities of the concrete matrix and their effects on the material behavior of the filaments should also be carefully examined.

- Confirmed estimations of the filament material parameters are an absolute requirement in order to correctly apply a rheological material model of realistic filament yarn behavior.

\section{ACKNOWLEDGEMENTS}

The authors gratefully acknowledge the financial support of this research from Deutsche Forschungsgemeinschaft DFG (German Research Foundation) within the Sonderforschungsbereich SFB 528 (Collaborative Research Center) "Textile Reinforcement for Structural Strengthening and Retrofitting" at Technische Universität Dresden as well as their colleagues for providing all experimental data.

\section{REFERENCES}

[1] Banholzer B. Bond behaviour of a multi-filament yarn embedded in a cementitious matrix. Dissertation, RWTH Aachen, Institut für Bauforschung 2004.

[2] Bauer HW. Verhalten von glasfasern in zementsuspensionen Dissertation, Universität Erlangen-Nürnberg, Fachbereich Ingenieurwissenschaften 1979.

[3] Bentur A, Mindess S. Fibre reinforced cementitious composites. London and New York: Elsevier Applied Science 1990.

[4] Bogdanovich AE, Pastore CM. Mechanics of textile and laminated composites. Chapman and Hall Ldt., London, 1996.

[5] Herakovich CT. Mechanics of Fibrous Composites. New York: John Wiley \& Sons Inc 1998.

[6] Dasappa P, Lee-Sullivan P, Xiao X. Development of viscoplastic strains during creep in continuous fibre GMT composites. Compos Part B 2009-03-008.

[7] Dasappa P, Lee-Sullivan P, Xiao X, Foss P-H. Tensile creep of a long-fibre glass mat thermoplastic (GMT) composite. II. Viscoelastic-viscoplastic constitutive modelling. Polym Compos 2009; 1204-11.

[8] Schorn H, Schiekel M, Hempel R. Dauerhaftigkeit von textilen Glasfaserbewehrungen im Beton. Bauingenieur, 2004; 79: 86-94.

[9] Dasappa P. Constitutive modelling of creep in a long fiber random glass mat thermoplastic composite. Doctor-Thesis, University of Waterloo, Mechanical Engineering, Ontario, Canada, 2008. 
[10] Mui J. Viscoelastic-viscoplastic model to predict creep in a random chopped mat thermoplastic composite. Master-Thesis, University of Waterloo, Mechanical Engineering, Ontario, Canada, 2008.

[11] Abdkader A. Charakterisierung und modellierung der eigenschaften von AR-glasfilamentgarnen für die betonbewehrung. Dissertation, Technische Universität Dresden, Institut für Textil- und Bekleidungstechnik, 2004.

[12] Pauchard V, Brochado S, Chateauminois A, Campion H, Grosjean F. Measurement of sub-critical crack-growth rates in glass fibers by means of acoustic emissions. J Mater Sci Lett 2001; 20: 777-9.

[13] Mäder E, Plonka R, Gao S-L. Coatings for fibre and interphase modification in a cementitous matrix. Proceedings of the 2 . Colloqium on Textile Reinforced Structures, Dresden, 2003.
[14] Flügge W. Viscoelasticity. Springer-Verlag, Berlin, Heidelberg, New York, 1975

[15] Stein E, Barthold F-J. Elastizitätstheorie. In: Mehlhorn, G. (Hrsg.), Der Ingenieurbau, Grundwissen. Werkstoffe, Elastizitätstheorie. Verlag Ernst Sohn, Berlin, 1996; pp. S165-S428.

[16] Betten J. Kontinuumsmechanik: elasto-, plasto- und kriechmechanik. Springer-Verlag, Berlin, Heidelberg, 1993.

[17] Phan-Thien N. Understanding viscoelasticity: basics of rheologie. Springer-Verlag, Berlin, Heidelberg, New York, 2002.

[18] Trostel R. Materialmodelle in der ingenieurmechanik. ViewegVerlag, Braunschweig, Wiesbaden 1999.

(C) Seidel et al.; Licensee Bentham Open

This is an open access article licensed under the terms of the Creative Commons Attribution Non-Commercial License (http://creativecommons.org/licenses/by-nc/ $3.0 /$ ) which permits unrestricted, non-commercial use, distribution and reproduction in any medium, provided the work is properly cited 